\title{
THE TREATMENT OF EARLY SYPHILIS WITH PENICILLIN, NEOARSPHENAMINE, AND BISMUTH
}

\author{
BY \\ G. L. M. McELLIGOTT, F. J. G. JEFFERISS, and R. R. WILLCOX \\ From the Venereal Diseases Department, St. Mary's Hospital, Paddington
}

The yardstick of failure in the treatment of early syphilis is the incidence of continued sero-resistance, of clinical and serological relapse, or, very occasionally, of asymptomatic neurosyphilis demonstrated by changes in the cerebrospinal fluid. Experience has taught us that, with careful observation, the great majority of failures can be detected during the first two years. This is now the traditional minimum period of surveillance. The later manifestations, such as cardiovascular involvement, gummatous lesions, and neurosyphilis, take a good deal longer to appear, and any reports on the results of penicillin treatment must contain the reservation that these might possibly occur at a later date.

\section{Disappointing Results of Penicillin Treatment}

When the apparently phenomenal success of penicillin in the treatment of early syphilis was subjected to its first critical survey in the harsh light of the accumulated American statistics, it became apparent that the results were not as promising as had been hoped. With total dosages of from 1.2 to 2.4 million units, results were much the same whether the injections were given at two-, four-, or sixhourly intervals or whether the duration of treatment varied between four and fifteen days. Consequently an improvement in these results was not to be expected by further increasing the total dosage over the same period. Indeed, in experimental rabbit syphilis, Eagle and his colleagues (1946 a) observed that to double the dose over double the time was likely to achieve better results than to double the dose over the same time. In man the cumulative early failure rate for primary and secondary syphilis treated with 2.4 million units of penicillin over seven and a half days proved to be 15 per cent. at eleven months (Moore, 1946) and, as.was to be expected, this figure was higher for the secondary and lower for the sero-negative primary cases. After eighteen to twenty-four months the failure rate rose to between 25 and 35 per cent.
(Moore, 1948), though it is only fair to state that Sternberg and Leifer (1946), who treated 1,400 cases of early syphilis in the United States Army with 2.4 million units of penicillin over seven and a half days, and who observed 84 per cent. of these cases for a minimum of nine months, recorded success rates of 94.3 per cent. in 600 sero-negative primary, 89.9 per cent. in 564 sero-positive primary, and 83.0 per cent. in 236 secondary cases.

It is often impossible to decide whether a case is one of mucocutaneous relapse or of reinfection, but even when probable reinfections are excluded, the American civilian failure rate after eighteen to twenty-four months is between 15 and 25 per cent. It is significant that both reinfections and relapses seem to be far more common after modern intensive schemes of treatment, irrespective of whether these consist of arsenicals and bismuth or of penicillin, and that they were seldom seen in the days of prolonged treatment with the time-honoured drugs. After only 1 to 4 injections of arsphenamine the incidence of infectious relapse was said to be 65 per cent. This dropped to 12.5 per cent. after 5 to 9 injections, while after three full courses of ten injections of neoarsphenamine and bismuth it was as low as 1.2 per cent. (Moore, 1943).

Though Eagle and his colleagues (Eagle, 1946 b) have shown that penicillin and arsphenoxide have a true synergist action in the treatment of animal syphilis and that bismuth has a further additive effect, when comparable dosages of the three drugs were tried in the human disease the results were no better than after penicillin alone (Heller, 1947). Such a method was tried in the British Army at home, 2.4 million units of penicillin over seven and a half days being combined with ten daily injections of $60 \mathrm{mg}$. of arsphenoxide. One of us (Willcox, 1947) has reviewed the results in 405 male patients treated by this method. Of these, only 75 were in the secondary stage, and the follow-up was not nearly as prolonged as in the present series, only 
20 per cent. of the total being seen after four to six months. In spite of this, no less than eighteen failures were noted, thirteen of them with dark-field positive lesions ; one was consistently sero-resistant, and four relapsed serologically. Apart from three of the failures which occurred at seven, eight, and eleven months, the remainder were noted during the first five months after treatment.

The fact that commercial penicillin has been shown to contain undefined proportions of the comparatively inactive penicillin IV (K) has justified Harrison's decision of three years ago not to recommend its exclusive use in the treatment of early syphilis, but to advise that one standard course of neoarsphenamine and bismuth be given in addition (Harrison, 1945). This procedure is now fairly general in most British clinics, and the Army and the Royal Air Force have adopted a similar scheme of treatment-a total of 4 million units of penicillin in ten days being combined with ten weekly injections of neoarsphenamine and bismuth.

\section{Patients Treated at St. Mary's Hospital}

At St. Mary's Hospital, London, since January, 1946, we somewhat intensified the course of neoarsphenamine and bismuth by giving both men and women patients twelve injections of $0.45 \mathrm{~g}$. neoarsphenamine and $0.2 \mathrm{~g}$. bismuth at four-day intervals, or at most twice weekly, in addition to a course of 4 million units of penicillin, either by eight single daily injections in oil-beeswax or in aqueous solution with round-the-clock divided doses. As a general rule the penicillin was not given until after the third arsenical injection, so that there should be no possibility of a ninth-day toxicoderma being confused with a penicillin urticaria. To minimize Herxheimer effects the initial dose of neoarsphenamine was $0.15 \mathrm{~g}$. in secondary cases and $0.3 \mathrm{~g}$. in those with primary syphilis.

The Patients.-Up to December 31, 1946, 150 male and 125 female patients had been treated on these lines. An additional 25 patients defaulted before the completion of treatment and are not included in the series. The average age of the men was 32 and of the women 29 years. The diagnoses are summarized in Table I.

The comparatively low incidence of primary syphilis in women is well shown, and attention is drawn to the relatively high number of secondary cases in this series, 124 out of a total of 275 . $T$. pallidum was isolated in 123 ( 82 per cent.) of men and 87 (69.6 per cent.) of women.

Penicillin.-Commercial penicillin was used throughout, either the sodium salt in aqueous solution or the calcium salt in oil-beeswax mixture. The more recent products
TABLE I

SUMMARY OF DIAGNOSES OF PATIENTS TREATED AT ST. MARY'S HOSPITAL BY NEOARSPHENAMINE, BISMUTH, AND PENICILLIN

\begin{tabular}{|c|c|c|c|c|c|}
\hline \multirow[b]{3}{*}{$\begin{array}{l}\text { Sero-negative primary } \\
\text { syphilis } \\
\text { Sero-positive primary } \\
\text { syphilis } \\
\text { Secondary syphilis }\end{array}$} & & \multicolumn{2}{|c|}{ Men } & \multicolumn{2}{|c|}{ Women } \\
\hline & & No. & $\%$ & No. & $\%$ \\
\hline & $\begin{array}{l}\cdots \\
\cdots \\
\cdots\end{array}$ & $\begin{array}{l}58 \\
\\
52 \\
40\end{array}$ & $\begin{array}{l}38 \cdot 6 \\
34 \cdot 7 \\
26 \cdot 7\end{array}$ & $\begin{array}{l}13 \\
\\
28 \\
84\end{array}$ & $\begin{array}{l}10.4 \\
22.4 \\
67.2\end{array}$ \\
\hline Total & .. & 150 & & 125 & \\
\hline
\end{tabular}

used are said to contain a very high proportion of penicillin G, but no definite percentage of this " fraction" is guaranteed by the manufacturers. Half the women and two-thirds of the men were treated as out patients with eight daily intramuscular injections of 500,000 units of penicillin in oil-beeswax suspensions of various brands. Nine patients received less than 2.4 million units, 65 were given 2.4 million units exactly, 91 (many of whom were temporary defaulters who had failed to complete the prescribed course) received 3.0 to 3.6 million units, 105 had 4 million units exactly, and 5 received more than this amount.

Neoarsphenamine.-Because of design, default, or the deterrent of toxic effects, the total dosage shows some variation, 23 cases being given none at all, 38 less than $2 \mathrm{~g}$., 38 from 2 to $4 \mathrm{~g}$., 158 from 4 to $6 \mathrm{~g}$., and 18 over $6 \mathrm{~g}$.

Bismuth.-Intramuscular injections of oxychloride of bismuth were given and, as with the neoarsphenamine, the maximum of caution was exercised in the event of possible toxic effects, either drug being discontinued in the face of minimal signs of intolerance. Nineteen patients received less than $1 \mathrm{~g}$. (equivalent bismuth metal), 78 had from 1 to $2 \mathrm{~g}$., 134 from 2 to $3 \mathrm{~g}$., and 44 more than $3 \mathrm{~g}$.

\section{Toxic Effects}

Penicillin.-Local reactions were not always recorded but were not usually severe. They often followed inadvertent subcutaneous injection of penicillin-oil-beeswax mixtures in obese women. Generalized penicillin urticaria was observed in seven patients and was for the most part treated with " benadryl."

Neoarsphenamine.-Thirty-two reactions severe enough to interfere with treatment were observed in 30 male ( 20 per cent.), and in 34 female patients (27.2 per cent.) there were 37 reactions. These are classified in Table II.

It will be observed that the toxic effects of both the arsenical drug and the bismuth were somewhat commoner in women than in men, an exception being hepatitis, now known to be due to a syringetransmitted virus and to be commoner among men. 
TABLE II

REACTIONS IN PATIENTS RECEIVING NEOARSPHENAMINE

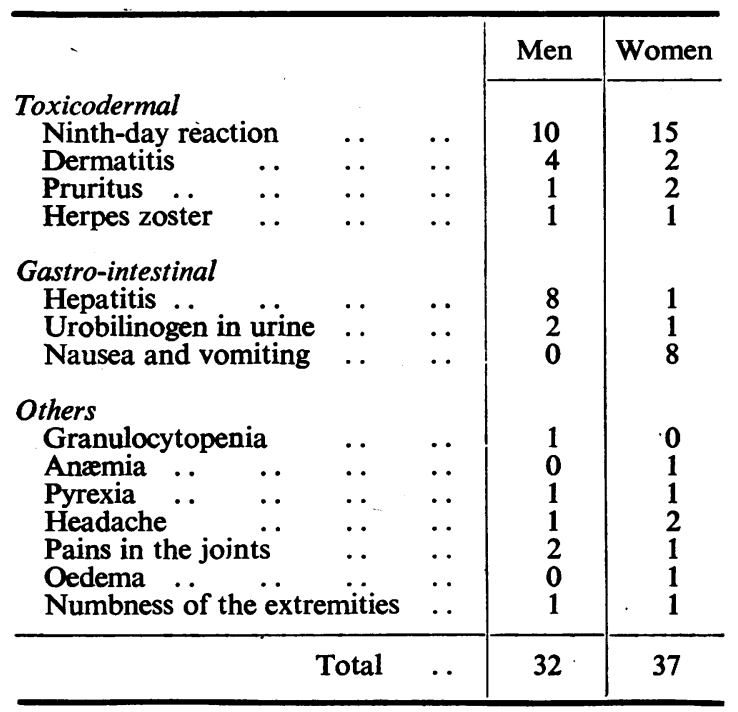

As these cases represent the cost of the clinical results, it is right not to minimize them.

One man developed granulocytopenia after six arsenical injections $(2.7 \mathrm{~g}$.). His total white count fell to 4,400 per c.mm. (neutrophils 3 per cent.). He recovered after treatment with penicillin and was in hospital for sixteen days.

Two of the male cases of dermatitis were severe, one remaining in hospital for three weeks and another being treated as an out patient for over five months.

Three of the male patients with jaundice had to be kept in bed for over two weeks, a fourth defaulted deeply jaundiced after three weeks, and a fifth was treated as an out patient for six weeks. Other side effects in men were not severe.

Of the women, the sole patient with hepatitis, was in hospital for fifty-one days ; another patient developed generalized exfoliative dermatitis and was treated with BAL and kept in hospital for forty-four days. The remainder were not seriously ill.

\section{Surveillance}

After the completion of treatment patients were instructed to return for clinical and serological examination once a month for six months, then quarterly for a year and six-monthly for a further year. In the second year an examination of the cerebrospinal fluid was to be made. $U p$ to the present 17 men and 13 women have had this test, all with very satisfactory results. The very low incidence of fluid abnormalities (5 in 719 patients tested) in Sternberg and Leifer's U.S. Army cases treated with penicillin alone suggests that asymptomatic neurosyphilis is a very unlikely eventuality (Sternberg and Leifer, 1946). Simultaneous Wassermann and Kahn tests were invariably made at every serological examination.

The success of the "follow-up" to date has been gratifying. Fifty-six men and women (20.7 per cent.) have been followed up for eighteen months or over, $102(37.1$ per cent.) for fifteen months or over, 150 (54.5 per cent.) for twelve months or over, 193 (70.2 per cent.) for nine months or over, 215 (78.1 per cent.) for six months or over, $240(87.3$ per cent.) for three months or over, and 35 patients (12.7 per cent.) for less than three months.

\section{Successes and Failures to Date}

Men.- Of the 92 sero-positive primary and secondary cases, 34 had become. negative by three months and 28 defaulted. Of the remaining 30 , 15 were negative at four months and 9 more had defaulted : 3 became negative after six and 2 after nine months. One patient with a slowly declining titre still had a positive Kahn test but a negative Wassermann at the thirteenth month.

One patient whose blood became negative at six months had an apparent sero-relapse at nine months but defaulted before this could be confirmed (Case 1). A second sero-positive primary case developed dermatitis after four injections of arsenic and bismuth in addition to penicillin. He defaulted but returned one year later with an indurated scrotal sore in which $T$. pallidum was not found at one examination. His Wassermann and Kahn tests were strongly positive but he again defaulted immediately (Case 2).

Of the 58 sero-negative patients, one defaulted after treatment, returning a year later with strongly positive blood tests : he again ceased to attend before this could be confirmed (Case 3). Another defaulted after five months, to return in the seventh month with an indurated non-ulcerated plaque on the dorsum of the penis from which $T$. pallidum could not be recovered. Strongly positive Wassermann and Kahn reactions in the blood, and negative spinal fluid findings were obtained. Though clinically the lesion was more like that of relapse, there had been repeated risks with strangers during the preceding weeks (Case 4).

Thus four probable failures, two of clinical and two of sero-relapse are noted in the $\mathbf{1 5 0}$ male cases.

Women.-Of the 112 sero-positive primary and secondary cases, 52 were negative at three months and 8 had defaulted. A further 19 were negative at four months and 3 more had defaulted, while, of remaining 30 patients, 14 were negative at five months, 11 at six to eight months and 5 at nine to twelve months. Many of these may have become negative before the time stated, but did not attend at an earlier date.

Three patients showed what might be termed " serological rebound," in that, though their blood became 
negative at four, four, and eight months respectively, 2 of them showed weakly positive changes after seven and twelve months, becoming completely negative and remaining so after fifteen and sixteen months, though the third continued to show flickering weakly positive results still evident at twenty-one months, the cerebrospinal fluid being normal. Though this case must be classified as a failure, it should be added that there is some doubt about the stage the disease had reached when treatment was commenced. Though the initial blood tests were strongly positive, the signs of secondary syphilis were dubious and $T$. pallidum was not isolated (Case 5).

One patient with sero-positive primary syphilis had a definite serological relapse. The blood became negative at three months but repeated tests at eleven and twelve months gave strongly positive results (Case 6). Another with secondary syphilis was known to be sero-negative at twelve months, but when next seen at seventeen months showed mildly positive blood tests which were unable to be confirmed because of default (Case 7). Yet another with secondary syphilis defaulted before treatment was complete and, when seen eighteen months later, had a strongly positive serology and was re-treated (Case 8).

There were two clinical failures. One, with seropositive primary syphilis, defaulted after receiving four million units of penicillin plus four injections of neoarsphenamine and bismuth. She returned after eleven months with a genital ulcer at a new site from which $T$. pallidum was readily recovered, the Wassermann and Kahn tests being strongly positive. A risk with an untraceable consort three weeks previously was admitted (Case 9). The other, who had received full treatment for secondary syphilis, was completely sero-negative by the fifth month, and remained so consistently until seventeen months, when a negative Wassermann test was associated with a mildly positive Kahn reaction. Two months later both tests were strongly positive, and numerous vulvar erosions and a small ulcer near the

TABLE III

SUMMARY OF CASES

\begin{tabular}{|c|c|c|c|c|c|c|c|}
\hline No. & Type of failure & Diagnosis & $\begin{array}{l}\text { Penicillin : } \\
\text { mega } \\
\text { units }\end{array}$ & $\begin{array}{l}\text { Nature of } \\
\text { vehicle or } \\
\text { solvent }\end{array}$ & $\begin{array}{l}\text { Neo- } \\
\text { arsphena- } \\
\text { mine } \\
(\mathrm{g} .)\end{array}$ & $\begin{array}{c}\text { Bismuth } \\
\text { oxychloride } \\
\text { (g.) }\end{array}$ & Complications \\
\hline & & & & MEN & & & - \\
\hline 1 & Sero-relapse & $\begin{array}{l}\text { Sero-positive } \\
\text { primary }\end{array}$ & $3 \cdot 0$ & Oil-wax & $3 \cdot 35$ & $1 \cdot 6$ & $\begin{array}{l}\text { Defaulted after } 8 \\
\text { arsenical injections }\end{array}$ \\
\hline 2 & $\begin{array}{l}\text { Clinical } \\
\text { ? reinfection } \\
\text { ? relapse }\end{array}$ & $\begin{array}{l}\text { Sero-positive } \\
\text { primary }\end{array}$ & $4 \cdot 0$ & Aqueous & 1.95 & $1 \cdot 0$ & Dermatitis ; default \\
\hline 3 & Sero-relapse & $\begin{array}{c}\text { Sero-negative } \\
\text { primary }\end{array}$ & $3 \cdot 0$ & Oil-wax & 0.45 & $1 \cdot 4$ & Dermatitis \\
\hline 4 & $\begin{array}{l}\text { Clinical } \\
? \text { reinfection } \\
\text { ? relapse }\end{array}$ & $\begin{array}{l}\text { Sero-negative } \\
\text { primary }\end{array}$ & $3 \cdot 0$ & Oil-wax & $4 \cdot 5$ & $2 \cdot 0$ & Mild dermatitis \\
\hline & & & & WOMEN & & & \\
\hline 5 & Sero-relapse & ? Secondary & $2 \cdot 4$ & Aqueous & $1 \cdot 25$ & $1 \cdot 8$ & Ninth day erythema \\
\hline 6 & Sero-relapse & $\begin{array}{l}\text { Sero-positive } \\
\text { primary }\end{array}$ & $3 \cdot 0$ & Aqueous & $4 \cdot 35$ & $2 \cdot 0$ & Pruritus \\
\hline 7 & Sero-relapse & Secondary & $2 \cdot 4$ & Aqueous & 4.05 & $1 \cdot 8$ & Nil \\
\hline 8 & $? \stackrel{?}{\text { Sero-relapse }}$ & Secondary & $3 \cdot 0$ & Aqueous & $2 \cdot 1$ & $1 \cdot 2$ & Default \\
\hline 9 & $\begin{array}{c}\text { Clinical } \\
\text { ? relapse } \\
\text { ? reinfection }\end{array}$ & $\begin{array}{l}\text { Sero-positive } \\
\text { primary }\end{array}$ & -4.0 & Oil-wax & 1.65 & 0.8 & Default \\
\hline 10. & $\begin{array}{c}\text { Clinical } \\
\text { ? relapse } \\
\text { ? reinfection }\end{array}$ & Secondary & $3 \cdot 0$ & Aqueous & $5 \cdot 55$ & $2 \cdot 4$ & Nil \\
\hline
\end{tabular}


anus were noted from which $T$. pallidum was easily recovered. There was some suggestion, unfortunately unconfirmed, that the husband may have been also infected (Case 10).

A summary of the above cases is provided in Table III.

\section{Summary and Conclusions}

Two hundred and seventy-five patients, 151 with primary and 124 with secondary syphilis, were treated with penicillin, neoarsphenamine, and bismuth for from six to ten weeks, the dosage of penicillin varying from 2.4 to 4 million units given over a period of seven and a half to twelve and a half days.

Two-thirds of the male patients and half the females were treated as out patients with daily - injections of penicillin-oil-beeswax mixtures. The remainder were admitted to hospital and given aqueous penicillin in a dosage of 40,000 to 75,000 units every three to four hours, the great majority receiving 50,000 units four-hourly. A greater number of failures were noted in the smaller number of patients receiving aqueous penicillin.

Toxic effects following the arsenical-injections were not negligible and in ten patients they were severe.

Fifty-four per cent. of the patients were followed for twelve to eighteen months or over, 70.2 per cent. for nine months or over, and 78.1 per cent. for six months or over.

Ten failures were noted among the series. Four had recent genital lesions, and all had positive serum reactions. Critical examination might decrease rather than increase this number in the light of the possibility of reinfection in four cases. The failure rate is probably in the region of 4 to 7 per cent. at twelve months, which compares favourably with that of 15 per cent. at the same period for patients treated with penicillin alone.

It is believed that prolongation of the total treatment time has lowered the incidence of infectious relapse and in some cases perhaps prevented further reinfection from regular consorts (so-called "ping-pong syphilis").

We also feel that it is possible that the treatment time is of such a length as to impress the patient with the importance of an adequate follow-up, though not long enough to weary him into default.

It remains to be seen whether these good results can be achieved without resort to the toxic arsenical drugs and whether penicillin combined with bismuth, or even penicillin alone given over a longer period, will prove to be adequate treatment for early syphilis.

Our thanks are due to our colleagues Doctors $\mathbf{A}$. W. Frankland, C. J. V. Helliwell, and Lucien Read, Assistant Medical Officers in the Department, and to Dr. R. H. Gorrell, our serologist, without whose help this study would not have been possible.

\section{Addendum}

Since going to press we have to report a further serological relapse in a male case of secondary syphilis. The patient received eight daily injections of penicillin in oil-beeswax, 500,000 units, in addition to a full course of neoarsphenamine, $5.4 \mathrm{~g}$., and bismuth, $2 \cdot 2 \mathrm{~g}$. The Wassermann and Kahn tests became negative one month after the end of treatment and relapsed to strongly positive eleven months later (confirmed by repetition). There were no clinical signs of syphilis, and the cerebrospinal fluid was normal. The only admitted risk of infection occurred three weeks before the serological relapse, but it has not been possible to examine this contact.

\section{REFERENCES}

Eagle, H., Magnuson, H. J., and Fleischman, R. (1946a). Johns Hopk. Hosp. Bull., 79, 168.

- _ - (1946b). J. vener. Dis. Inf., 27, 3.

Harrison, L. W. (1945). Practitioner, 155, 223.

Heller, J. R. (1947). Personal communication.

Moore, J. E. (1943). " Modern Treatment of Syphilis." Ballière, Tindall and Cox, London. p. 25.

- (1946). "Penicillin in Syphilis." C. C. Thomas, Springfield, Illinois. p. 155.

, (1948). Brit. J. vener. Dis., $24,1$.

Sternberg, T. H., and Leifer, W. (1946). J. Amer. med. Ass., 133, 1.

Willcox, R. R. (1947). J. R. Army med. Cps., 89. 49. 